\title{
A network approach to identify bioregions in the distribution of Mediterranean amphipods associated with Posidonia oceanica meadows
}

\author{
Bruno Bellisario ${ }^{\text {Corresp., } 1}{ }^{\text {, Federica Camisa }}{ }^{1}$, Chiara Abbattista $^{1}$, Roberta Cimmaruta $^{1}$ \\ 1 Department of Ecological and Biological Sciences, Università degli Studi della Tuscia, Viterbo, Italy \\ Corresponding Author: Bruno Bellisario \\ Email address: bruno.bellisario@unitus.it
}

Although amphipods are key components of the macro-fauna associated with Posidonia oceanica meadows, to date no studies focused on the structure and diversity of their assemblages across the whole Mediterranean Sea. Here, we applied a network approach based on modularity on a dataset mined from literature to identify biogeographic modules and to assess the biogeographic roles of associated localities. We also correlated the patterns evidenced with the biogeographic distribution of amphipod groups by means of a multivariate analysis. Modularity analysis highlighted four biogeographic modules bounded by the main Mediterranean biogeographic divides and evidenced a decrease in species diversity along a NW-SE gradient. Assemblages associated with Central-Western Mediterranean and, to a lesser extent, Tunisian modules showed the highest species richness and were identified as hubs, characterized by species with regional distributions that behave as source in a biogeographic context. The paleogeographic history of the host seagrass and the ecology of associated amphipods, both suggest the joint effect of species persistence and post-Last Glacial Maximum expansion in explaining the pattern of amphipod distribution in the Mediterranean Sea. 


\author{
1 A network approach to identify bioregions in the \\ 2 distribution of Mediterranean amphipods associated with \\ 3 Posidonia oceanica meadows \\ 4 \\ 5 B. Bellisario, F. Camisa, C. Abbattista, R. Cimmaruta \\ 6 \\ 7 Department of Ecological and Biological Sciences, Università degli Studi della Tuscia, Viterbo, \\ 8 Italy \\ 9 \\ 10 Corresponding Author: \\ 11 Bruno Bellisario \\ 12 Largo dell'Università Snc Blocco C, Viterbo, Italy \\ 13 Email address: bruno.bellisario@unitus.it
}




\section{ABSTRACT}

Although amphipods are key components of the macro-fauna associated with Posidonia oceanica meadows, to date no studies focused on the structure and diversity of their assemblages across the whole Mediterranean Sea. Here, we applied a network approach based on modularity on a dataset mined from literature to identify biogeographic modules and to assess the biogeographic roles of associated localities. We also correlated the patterns evidenced with the 22 biogeographic distribution of amphipod groups by means of a multivariate analysis. Modularity 23 analysis highlighted four biogeographic modules bounded by the main Mediterranean 24 biogeographic divides and evidenced a decrease in species diversity along a NW-SE gradient. 25 Assemblages associated with Central-Western Mediterranean and, to a lesser extent, Tunisian 26 modules showed the highest species richness and were identified as hubs, characterized by 27 species with regional distributions that behave as source in a biogeographic context. The 28 paleogeographic history of the host seagrass and the ecology of associated amphipods, both 29 suggest the joint effect of species persistence and post-Last Glacial Maximum expansion in 30 explaining the pattern of amphipod distribution in the Mediterranean Sea. 
32

33

34

35

36

37

38

39

40

41

42

43

44

45

46

47

48

49

50

51

52

53

54

55

56

57

58

59

60

61

62

63

64

65

66

67

68

69

70

71

\section{INTRODUCTION}

The Mediterranean Sea represents only $0.3 \%$ of ocean waters, yet it is a recognized hot-spot of biodiversity hosting about 17,000 species (Coll et al., 2010; Bianchi et al., 2012). This high diversity stems from a combination of oceanographic, ecological and biogeographic features allowing the coexistence of species of Atlantic origin with temperate and subtropical organisms (Coll et al., 2010). Latitudinal clines of environmental variables (mainly temperature and salinity) combined with marine currents resulted in a generalised latitudinal gradient of both primary production and species richness, decreasing from north-eastern to south-western regions (Coll et al., 2010; Lejeusne et al., 2010). Accordingly, biogeographic sectors were identified within the Mediterranean Sea, each characterized by both different biota and ecological parameters (Bianchi et al., 2012).

Although general patterns of biodiversity distribution within the Mediterranean Sea have been well described (Coll et al., 2010; Bianchi et al., 2012), studies concerning patterns and mechanisms of species co-occurrence across the whole Mediterranean basin are restricted to a relatively small number of organisms (e.g., Arvanitidis et al., 2002; Gerovasileiou \& Voultsiadou, 2012). Moreover, geographically widespread and ecologically broadly adapted groups have been only seldom studied according to habitat-related subdivisions (Sevastou et al., 2013). In this work, we focused on amphipod crustaceans associated with Posidonia oceanica (L.) Delile, 1813 meadows, since they represent one of the most relevant components of the vagile fauna of this key seagrass, endemic to the Mediterranean Sea.

Posidonia oceanica plays a fundamental role in ecosystem engineering along the Mediterranean coasts, providing important ecosystem functions, including oxygen production, food and shelter for associated species, as well as reduction of coastal erosion (Boudouresque, Mayot \& Pergent, 2006). The complexity of this multi-layered and three-dimensional habitat allows a great variety of associated fauna to live into the canopy, rhizomes and mattes, making the meadows a strikingly biodiversity-rich habitat within the Mediterranean (Buia, Gambi \& Zupo, 2000). Among the vagile fauna associated with meadows, amphipod crustaceans are one of the dominant groups, showing high abundance and diversity of species (Mazzella, Scipione \& Buia, 1989; Gambi et al., 1992; Sturaro et al., 2015). Amphipods are key ecological components of seagrass habitats, due to their role in transferring energy across the system, and represent an important trophic resource for higher predators such as fish (Pinnegar \& Polunin, 2000; Zakhama-Sraieb, Ramzi-Sghaier \& Charfi-Cheikhrouha, 2011; Michel et al., 2015; Bellisario et al., 2016). Amphipods associated with $P$. oceanica meadows feed preferentially on macroepiphytes, algae and associated detritus (Michel et al., 2015), establishing a sort of facilitative interaction with the host plant by promoting the seagrass growth and obtaining protection against predation (Valentine \& Duffy, 2006).

Despite the importance of amphipods in seagrass systems, a comprehensive study on their biogeographic patterns at the whole Mediterranean scale is still lacking. Available data include mainly check-lists and local studies based on classical diversity index (Gambi et al., 1992; 
72 Diviacco, 1998; Como et al., 2008; Scipione \& Zupo, 2010; Bedini et al., 2011; Zakhama-Sraieb, 73 Ramzi-Sghaier \& Charfi-Cheikhrouha, 2011; Sturaro et al., 2015), which can foster

74 biogeographic studies using innovative approaches.

75 Recently, specific metrics rooted in network analysis have been successfully applied in a 76 biogeographic context, outperforming classic approaches as clustering methods in the 77 identification of bioregions (Carstensen \& Olesen, 2009; Vilhena \& Antonelli, 2015; Bloomfield, 78 Knerr \& Encinas-Viso, 2018). In particular, modularity (i.e., the tendency of a network to 79 subdivide in densely connected modules or clusters) has proved powerful in detecting groups of 80 areas and/or species closely connected together (i.e., biogeographical modules, sensu Carstensen 81 et al., 2012; 2013). This approach also provides relevant insights into the processes driving the 82 assembly of communities by evaluating the importance of each local assemblage (represented by 83 nodes) in terms of network connectivity (Bloomfield, Knerr \& Encinas-Viso, 2018). Specific 84 metrics related to the number of links within and between biogeographic modules can be used as 85 indirect estimators of richness and endemism and provide information on the source/sink role of 86 localities (Carstensen et al., 2012; 2013; Bloomfield, Knerr \& Encinas-Viso, 2018).

87 In this work, we mined data from literature on the distribution of amphipods associated with $P$. 88 oceanica meadows along the Mediterranean basin. We then used a network approach based on 89 modularity: 1) to detect biogeographic structure; 2) to correlate the patterns evidenced with the 90 current knowledge on the biogeographic distribution and ecological features of amphipod 91 groups; 3) to compare amphipods diversity with the paleogeographic history of Mediterranean 92 Sea and biogeographic history $P$. oceanica seagrass. The results obtained are discussed with the 93 aim to provide insights on the patterns of amphipod diversity and distribution across the 94 Mediterranean basin. 
96

97

98

99

100

101

102

103

104

105

106

107

108

109

110

111

112

113

114

115

116

117

118

119

120

121

122

123

124

125

126

127

128

129

130

131

132

133

134

135

\section{MATERIALS \& METHODS}

\section{Study area and starting dataset}

An extensive survey of the literature was conducted to obtain all available information on the presence of amphipods from $P$. oceanica meadows across different regions of the Mediterranean Sea. We filtered the available literature to obtain comparable data in terms of sampling season, depth and methods (see Supplemental Materials \& Methods S1), so recovering data from 11 papers (Diviacco, 1988; Scipione et al., 1996; Scipione, 1998; Sanchéz-Jerez et al., 2000; Zakhama-Sraieb et al., 2006, 2010; Bedini et al., 2011; Sturaro et al., 2014, 2015; Bellisario et al., 2016, Camisa et al., 2017). Data were checked for possible taxonomic issues by updating species nomenclature according to WoRMS, so that species names reported in Table S1 correspond to present day taxonomic assignment (see Supplemental Materials \& Methods S1 for further explanations). The final dataset (available as Supporting Dataset in Supplemental Materials \& Methods) included 147 amphipod species from 28 localities: nine located in Tunisia, 16 in Italy (Tyrrhenian, Adriatic and Ionian Sea), two in Spain and one in Corsica (France). The literature source for each locality and each species is listed in Supplemental Materials \& Methods S1. Available data covered a large portion of the Mediterranean basin (Fig. 1), and were distributed in regions characterized by different geographic, hydrological and geological features, as well as by differences in the potential connectivity due to the general circulation models (Bianchi \& Morri, 2000; Bianchi, 2007; Berline et al., 2014).

Information about the biogeographic distribution of observed amphipods were obtained from Bellan-Santini \& Ruffo (2003), which classified over 400 species of Mediterranean benthic amphipods in twelve macro-categories on the basis of their current distribution: WM, West Mediterranean; EM, East Mediterranean; Adr, Adriatic Sea; ME, Mediterranean endemics; Afr, African coasts from Ceuta to Cap Vert; Ib, Iberian coasts; Fr, French coasts; Br, British coasts; Norw, Norwegian coasts; Arct, Arctic Sea; Ind-P, Indo-Pacific Ocean; Cosm, Cosmopolitan. Here, species with an Atlantic distribution were clumped in two main categories from the five proposed by Bellan-Santini \& Ruffo (2003): ATL, Atlantic Sea (Iberian, French and British coasts) and NATL, North Atlantic Sea (Norwegian and Arctic regions), so that our final distribution comprised nine different categories.

\section{Network analysis}

To provide insights into the biogeographic distribution of amphipod assemblages, a thresholding approach was used to identify groups of localities having stronger similarity in terms of community composition (Kivelä, Arnaud-Haond \& Saramäki, 2015).

Data were ordered as a species/incidence matrix, whose entries represent the presence of species (rows) at each locality (columns). A weighted network, where localities represent nodes and links the strength of connections, was built using the Jaccard index on the species/incidence 
136 matrix, to derive a similarity distance matrix of species co-occurrence. Values ranged from 0 , 137 when two localities were identical in amphipod composition, to 1, when they shared no taxa, so 138 that links with higher weights indicated low similarity between localities, and vice versa. The 139 thresholding approach was then applied to identify closely related localities by finding the critical value describing the threshold similarity among pairs (i.e. percolation network).

Percolation networks are becoming increasingly used in ecological studies since they allow identifying relationships among nodes (i.e., populations, species, critical scales in landscape ecology) with the advantage of not requiring any a priori knowledge of a threshold value (Rozenfeld et al., 2008; Fletcher et al., 2013; Bellisario, 2018). This value was measured by removing distances in decreasing order (i.e., most dissimilar localities), until the network reached the threshold value beyond which it becomes fragmented into disconnected clusters. The identification of this value is obtained by calculating the average cluster size $\langle L\rangle$ that is, the average number of localities belonging to an $l$-size cluster, as a function of the last threshold distance value beyond which links were removed (Stauffer \& Aharony, 1992):

$$
<L>=\frac{1}{N} \sum_{l<l_{\max }} l^{2} n_{l}
$$

153

where $N$ is the total number of localities not included in the largest cluster $\left(l_{\max }\right)$ and $n_{l}$ is the number of clusters containing $l$ localities. Basically, each time a distance value is removed from the network, localities are redistributed in clusters of different sizes, from largest to smallest. This procedure is therefore iterated until the critical threshold is identified in the transitional region characterized by a strong decrease in $\langle L\rangle$ where the network becomes disconnected (for more information about percolation theory, refer to Stauffer \& Aharony, 1992). Here, we used the methodology described in Rozenfeld et al. (2008) and implemented in the package ‘sidier' (Muñoz-Pajares, 2013) of R (R Development Core Team, 2018).

\section{Modularity}

After identifying the minimum set of pairwise similarities between localities, we tested for the presence of a significant pattern of aggregation between localities, and if this pattern reflected a geographic component. To this end, we measured the modularity $(Q)$, which is defined as the degree to which a network can be subdivided in aggregated sets of nodes (i.e., modules), where the within-module links are significantly higher than between-module ones (Newman \& Girvan, 2004; Fortunato, 2010). Modularity provides a formal description of the pattern of aggregation between species, populations or communities, being able to identify critical scales in specific ecological and evolutionary processes (Fletcher et al., 2013).

Modularity was measured by using the equation originally described by Newman and Girvan (2004): 
175

176

177

178

179

180

181

182

183

184

185

186

187

188

189

190

191

192

193

194

195

196

197

198

199

200

201

202

203

204

205

206

207

208

209

210

211

212

$$
Q=1 / 2 m \sum_{i, j}\left[A_{i j}-P_{i j}\right] \delta\left(C_{i}, C_{j}\right)
$$

where $m$ is the total number of links in the percolation network (see above), $A_{i j}$ is the matrix expressing the degree of similarity between localities $i$ and $j, \delta\left(C_{i}, C_{j}\right)$ is a matrix indicating whether $i$ and $j$ are members of the same module and $P_{i j}$ is the probability in the null model that a link exists between $i$ and $j$. The extent to which links are distributed within and among modules was tested against an appropriate null model, to correct the observed value of $Q$ by null model expectation. Here we used a simulated annealing algorithm (SA) to test for the significance of a modular partitioning by generating 1,000 null matrices having the same degree distribution as the original network. Under the SA algorithm, affiliation of nodes to modules has an accuracy of $90 \%$, and a significant modular structure was found if the empirical $Q$ value lies above the $95 \%$ confidence interval for $Q$ in the randomized networks (Guimerà \& Amaral, 2005).

Starting from the modular partition, we further assigned the role of each locality in the network by using two topological measures related to the number of species of the local fauna $(l$, local topological richness) and the distribution of its associated species to other modules ( $r$, regional topological linkage) (Carstensen et al., 2012). The two-dimensional space given by $l-r$ allows the subdivision of localities in: peripherals, few local and regional species; non-hub connectors, few local and many regional species; provincial hubs, many local and few regional species; connector hubs, many local and regional species (revised after Carstensen et al., 2012). Following Carstensen et al. (2012). Non-hub localities (i.e., peripherals and connectors) can be interpreted as sink, able to receive species from source localities both within their own module and of other modules. Conversely, hub-localities (i.e., provincial and connector hubs) can be interpreted as source for both their modules (module hubs) and the entire network (network hubs). As links in our network relate with patterns of similarity between assemblages, the role of localities allowed for a straightforward description of how amphipod diversity could have spread between different areas of the Mediterranean basin.

\section{Multivariate analysis}

To explore to what extent the measured network characteristics (i.e., modularity and nodes topology) were related to the biogeographic distribution of amphipods, we ran a between-group correspondence analysis (BGCA) on the 'sites x species-biogeographic classes' matrix, where groups were given by the identified modules. BGCA performs a classic Correspondence Analysis (CA) of the per-group centers of gravity, providing an ordination of the groups by maximizing the between-group variance (Baty et al., 2006). From the nine species-biogeographic classes derived from the literature (see above), data were aggregated by summing the number of species belonging to each class at a given site.

Peer] reviewing PDF | (2018:10:31949:2:0:NEW 7 Mar 2019) 


\section{RESULTS}

215

216

217

218

219

220

221

222

223

224

225

226

227

228

229

230

231

232

233

234

235

236

237

238

239

240

241

242

243

244

245

246

247

248

249

250

251

252

253

The final dataset obtained from literature showed that 147 amphipod species belonging to 77 genera have been identified to date in P. oceanica meadows from 28 Mediterranean localities (Supplemental Materials \& Methods S1).

\section{Modules identification}

The percolation network showed a co-occurrence similarity threshold of 0.74 , which means that sampling sites are expected to share no more than $74 \%$ of amphipod species. This leaded to a network structure of 28 localities joined by 104 links, showing a significant modular structure when compared with randomized models $(Q=0.466 \pm 0.005, P<0.001)$. Four distinct modules were identified, characterized by a clear geographic distribution: Central-Western Mediterranean (CWM), Tunisian (TUN), Ionian (ION) and Adriatic (ADR) (Fig. 2a).

Eleven localities constituted the Central-Western Mediterranean module (CWM), which spanned from the Spanish to southern Tyrrhenian coasts, including Lampedusa (LAM) and Marettimo (MART) Islands. This module contained the highest number of species (130), of which a high percentage were module exclusives (i.e., present in a single module). Eighty species were exclusively linked (i.e., observed) to the CWM module, which shared 20, 11 and two species with the TUN, ION and ADR modules, respectively, while 14 are in common among all the four modules (Fig. 2b). The CWM module also showed the highest number of Mediterranean endemics (sensu Bellan-Santini \& Ruffo, 2003) as, for example, species belonging to the genus Peltocoxa: P. gibbosa (Schiecke, 1977), P. mediterranea Schiecke, 1977 , P. marioni Catta, 1875 (Fig. 2b, Table 1 and Table S1 in Supplemental Materials \& Methods S1).

The Tunisian module (TUN) comprised all nine localities belonging to the Tunisian coasts and showed both a high number of species and a high percentage of module exclusives, for example the species belonging to the genus Elasmopus: E. brasiliensis (Dana, 1855), E. pectenicrus (Spence Bate, 1862), E. pocillimanus (Spence Bate, 1862). This module was also characterized by the lowest number of Mediterranean endemics (Fig. 2b, Table 1 and Table S1 in Supplemental Materials \& Methods S1).

Both the Adriatic (ADR, three localities) and Ionian (ION, three localities) modules were characterized by having a few species and a low percentage of module exclusives (Fig. 2b and Table 1). The ION module showed some Mediterranean endemics like Iphimedia minuta G. O. Sars, 1883 or Maera pachytelson Karaman \& Ruffo, 1971, while the ADR module showed a high percentage of cosmopolitan species.

The topological role of localities has been assessed by modularity analysis (Fig. 2c), so that each locality has been assigned to a category according to the topological linkage, i.e., local or regional. Localities with a few, local (i.e., module exclusive) species are considered as peripheral nodes (R1 in Fig. 2c), while nodes with a high number of species characterized by regional

Peer) reviewing PDF | (2018:10:31949:2:0:NEW 7 Mar 2019) 
254 distribution (i.e., shared among many modules) are considered as connector hubs (R4 in Fig. 2c).

255 Localities in the ADR and ION modules were all classified as peripherals or non-hub connectors 256 (R1 and R2 in Fig. 2c), meaning that amphipod assemblages in these localities are composed by 257 few local species and by a higher (although not very consistent) number of species having a 258 regional distribution (see Materials \& Methods). Localities in the CWM and TUN modules were 259 classified mainly as hubs, subdivided between provincial and connector hubs (R3 and R4 in Fig. 260 2c). More than half (54\%) of localities in the CWM module can be considered connector hubs, 261 characterized by many local and regional species, while most of localities in the TUN module 262 were classified as provincial hubs, so having a larger number of local than regional species (Fig. 263 2c). The highest values of species diversity are found in hub localities (R3 and R4), while the 264 lowest values of diversity were found in peripheral localities (R1 and R2) together with some 265 hubs, as the 9 TUN localities (Fig. 2c).

266

267

268

269 The first two principal dimensions of the BGCA accounted for almost $80 \%$ of the total inertia 270 (Fig. 3), showing that some biogeographic groups of species concur in explaining the observed 271 pattern of between-modules variance (Fig. 3). Mediterranean endemic species (ME) accounted 272 for almost $50 \%$ of the total variance explained by the first dimension of the BGCA, which was 273 associated with the pattern of distribution of assemblages in the CWM module. Indo-Pacific 274 (INDP) and African (AFR) species accounted for more than $30 \%$ of variance along the first 275 dimension (Fig. 3), providing a clear differentiation of the TUN module from all others.

276 Cosmopolitan species (COSMP) accounted for $20 \%$ of the between-module variance explained 277 by the second dimension of the BGCA, characterizing the pattern of ordination of the ADR 278 module (Fig. 3). With respect to the biogeographic role of localities, provincial and connector 279 hubs seemed to be characterized by both Mediterranean endemics (ME) and species of Indo280 Pacific distribution (INDP), while peripheral localities were characterized mainly by 281 cosmopolitan species (COSMP), although the overall pattern was not sharply defined (Fig. 3). 


\section{DISCUSSION}

284

285

286

287

288

289

290

291

292

293

294

295

296

297

298

299

300

301

302

303

304

305

306

307

308

309

310

311

312

313

314

315

316

317

318

319

320

321

322

\section{Modules are biogeographically based}

Our findings showed that amphipod assemblages are heterogeneous throughout the Mediterranean area, with a maximum of $74 \%$ of species shared among localities, and that these differences lay on a geographical base. Despite the network approach does not relay on spatial information, the identified modules correspond to four geographic regions of the Mediterranean Sea: Central-Western Mediterranean (CWM), Tunisian (TUN), Ionian (ION) and Adriatic (ADR). Each region is delimited by well-known barriers, such as the Almeria-Oran Front, the Sicily Channel and the Strait of Otranto (highlighted as n. 2, 5 and 6 in Fig. 1). All these barriers have been pointed out as the most relevant in accounting for by ecological and biogeographic heterogeneity across the Mediterranean Sea, and all of them set a quite abrupt change in salinity and temperature regimes of adjacent basins.

The Almeria-Oran Front (AOF) is the western boundary of the Central-Western module (CWM), corresponding to the range boundary of the Mediterranean endemic P. oceanica, unable to tolerate the low temperature and salinity of the Alboran Sea (Boudouresque, 2004).

Circulation patterns and changes in temperature and salinity across the Sicily Channel, both concur in partially preventing the dispersal of a number of species across the threshold of the Siculo-Tunisian Straits (Robinson et al., 1992; Coll et al., 2010). In our study, this is the divide between the CWM and TUN modules, with this latter grouping the localities along the Tunisian coasts characterized by the presence of the jet-like Algerian Current and Atlantic Ionian Stream (Pinardi \& Masetti, 2000). The Strait of Otranto delimits the Adriatic Sea, a semi-enclosed basin where several factors, as winds, tides and freshwater runoff from rivers, all determine peculiar low salinity and low winter temperatures (Falco et al., 2000; Lejeusne at al., 2010). This is the boundary between the ADR and ION modules, which moderately exchange water mass through the Albanian side of the Strait of Otranto (Orlic, Gacic \& Laviolette, 1992).

The boundaries between modules are represented by the most effective Mediterranean barriers, in agreement with the geographic patterns highlighted in other organisms studied at the whole basin scale. The areas corresponding to the Western and Eastern Mediterranean and to the Adriatic Sea have been historically considered as different biogeographic provinces, hosting differentiated species assemblages of macrophytes, diatoms and many animal groups (Ignatiades et al., 2009; Gambi, Lampadariou \& Danovaro, 2010). Among invertebrates, an analysis of the Mediterranean sponge regional diversity showed distinct assemblages from CW Mediterranean, Tunisia, Adriatic and Ionian Sea (Gerovasileiou \& Voultsiadou, 2012). Similar results were reported for benthic polychaetes, showing different assemblages in the Western and Central Mediterranean basins and in the Adriatic Sea (Arvanitidis et al., 2002), while deep-sea megafauna showed dissimilar community compositions in Western Mediterranean and Ionian basins (Tecchio et al., 2010).

Peer) reviewing PDF | (2018:10:31949:2:0:NEW 7 Mar 2019) 
323

324

325

326

327

328

329

330

331

332

333

334

335

336

337

338

339

340

341

342

343

344

345

346

347

348

349

350

351

352

353

354

355

356

357

358

359

360

361

362

\section{Modules diversity and species distribution}

The differentiation among the four modules depends on different aspects of assemblage diversity and composition. The assemblages characterized by higher diversity were all from the CWM module, and in particular were located in the Central Tyrrhenian area (e.g., CHIA, MOR, GIAN, TAV; Fig. 2b). Localities from ADR and ION modules showed the lowest diversity values, together with a few localities from CWM (MART, MED) and TUN (ZAP, RAF). A decreasing gradient in species richness from north-west to south-east is a generalized pattern in the Mediterranean Sea, with an overall animal species diversity $100 \%$ greater in the western than in the eastern basin in both vertebrates and invertebrates (Boudouresque, 2004; Coll et al., 2010). As an example, the diversity of deep-sea nematode assemblages decreases with depth but, when similar depths are compared, a longitude effect appears, with diversity decreasing eastward (Danovaro et al., 2008). A similar pattern was detected in deep-sea foraminifers, whose species richness decreases from western to eastern Mediterranean, likely mimicking the longitudinal cline of organic matter availability on the deep seafloor (Danovaro et al., 2010).

The biogeographic role of localities showed how assemblages differ among and within modules, by identifying hubs vs. peripheral localities. Localities with assemblages having a high number of species characterized by regional distribution (i.e., shared among many modules) are considered as connector hubs and are supposed to behave as source in a biogeographic context. On the opposite, localities where assemblages contain few, local species are labeled as peripheral nodes, and considered as sinks. Interestingly, nearly all the localities of CWM and TUN modules are classified as hubs, meaning that they share a large proportion of species with many other localities belonging to other modules, besides a relevant number of species among each other. On the contrary, all the localities from ADR and ION modules are considered as peripherals or ultra-peripherals, so having assemblages very similar at intra-module level and highly differentiated with respect to localities belonging to other modules. Both modules are characterized by a small number of module exclusive species, together with a sub-set of species found either in the whole basin or in the hub localities of the CWM module.

The identified modules differ not only in species richness and biogeographic roles of their associated localities, but also in the biogeographic distribution of the species found in various assemblages. The pattern recovered links species' richness and distribution, with low-richness modules characterized by species having wider distributions and vice-versa, which can be explained in the light of biogeographic considerations. For instance, Indo-Pacific and African species associated with warm waters typify the rich Tunisian assemblages, as for example those belonging to the genus Elasmopus (Fig. 3). Mediterranean endemics and, to a lesser extent, North-Atlantic species characterize the high diversity of CWM. Apherusa chiereghinii GiordaniSoika, 1949, Cressa cristata Myers, 1969, Gammaropsis crenulata Krapp-Schickel \& Myers, 1979, and the species belonging to the genus Peltocoxa are examples of Mediterranean endemics of the CWM module, while some species belonging to the genus Ampelisca, like $A$. serraticaudata Chevreux, 1888 and A. tenuicornis Lilljeborg, 1855, represent an example of 
363 temperate species of Atlantic origin inhabiting also the western part of the Mediterranean Sea.

364 This pattern is due to the well-known paleogeographic history of the basin, with particular regard

365 to the most recent cycles of Plio-Pleistocene glaciations (Coll et al., 2010). These climatic

366 oscillations induced temperate Atlantic species to periodically enter the Mediterranean Sea

367 where they originated vicariant endemic species as a result of geographic isolation and local

368 adaptation. Examples are species belonging to the genera Apherusa, Tritaeta and Tmetonyx,

369 which represent the cold component of the Mediterranean amphipod fauna (Bellan-Santini \&

370 Ruffo, 2003). For these reasons the Mediterranean Sea is considered as a 'diversity pump' from

371 the Atlantic and the identification of its biogeographic provinces largely rely on the distribution

372 of Mediterranean endemics (Bianchi \& Morri, 2000; Bianchi et al., 2012). Similarly, it has been

373 shown that species originated from warm faunas prevail in the south-eastern part of the

374 Mediterranean basin (Lejeusne et al., 2010). Accordingly, the presence of warm species as a

375 representative of the Tunisian coasts has been signaled for other invertebrates, e.g., sponges

376 (Gerovasileiou \& Voultsiadou, 2012).

377 Assemblages in the geographically confined ADR module are characterized mainly by widely

378 distributed species with cosmopolitan range. This observation, and the fact that only few species

379 are found exclusively in this module, both suggest that this area may be particularly difficult to

380 be colonized and behave as a sink, as shown by modularity analysis (Fig. 3c). This difficulty can

381 be related to both extreme environmental conditions and geographic isolation, so that only vagile

382 and tolerant species may enter and establish in this basin. Indeed, the Adriatic Sea is

383 characterized by low salinity and winter temperatures, together with a moderate water mass

384 exchange with the neighbouring Ionian Sea through the Strait of Otranto (Orlic, Gacic \&

385 Laviolette, 1992; Falco et al., 2000). Moreover, the Adriatic basin was largely dried during the

386 Last Glacial Maximum (LGM, 23K-19K years ago; Rohling et al., 2010), so that a significant

387 part of the Adriatic fauna has only recently re-colonized this basin. Within the poorly vagile

388 group of amphipods, which are brooding species lacking a pelagic larval stage, cosmopolitan

389 species are generally euryhaline, eurytherm and more prone to passive dispersal (Bellan-Santini

390 \& Ruffo, 2003), thus having the highest probability to reach and settle in the Adriatic habitat.

391 Accordingly, a recent checklist of opisthobranch Adriatic fauna signaled that the great majority

392 of species had an Atlantic-Mediterranean range, while only few were Mediterranean endemics

393 (Zenetos et al., 2016).

394

395

396

397

398

399

400

401

402

\section{Amphipod diversity and paleogeographic history of Posidonia oceanica}

Populations of $P$. oceanica inhabiting the western and eastern parts of the Mediterranean Sea are genetically differentiated, with those from the central Mediterranean around the Siculo-Tunisian Strait characterized by a higher genetic diversity (Arnaud-Haond et al., 2007; Serra et al., 2010). This pattern was interpreted as the result of a secondary contact zone between the western and eastern forms, each one originated by vicariance in glacial refugia during the Last Glacial Maximum (LGM) (Serra et al., 2010). A more recent study has superimposed Ecological Niche 
403 Modelling to phylogeographic data, highlighting the southern Mediterranean as the most 404 climatically suitable area during LGM, with particular regard to the central zone. This area was 405 then proposed as the main glacial refugium of the seagrass, thus explaining its higher genetic 406 diversity as due to the long-term persistence in this region (Chefaoui, Duarte \& Serrão, 2017). 407 Glacial refugia have been repeatedly pointed out as hot-spots and melting pots of diversity, 408 not only in terrestrial environments but also in marine habitats (Hewitt, 1999; 2004; Maggs et al., 409 2008). This diversity may concern both genetic lineages and community richness, in agreement 410 with the postulated relationship between habitat stability and community diversity (Hewitt, 2000; 411 Ives \& Carpenter, 2007). Within this frame, the high diversity and the hub role of assemblages in 412 TUN module can be explained by their localization in a glacial refuge area, as proposed by 413 Chefaoui, Duarte \& Serrão (2017). However, the same pattern characterized the CWM 414 assemblages, which are richer in species and share an even greater percentage of their species 415 with other modules. This finding however may be only apparently in contrast with the lower 416 presence probability of $P$. oceanica in the northern Mediterranean during LGM, if we consider 417 that amphipods living on $P$. oceanica are not exclusively found in this habitat.

418 Indeed, amphipods can actively choose their substratum, and this habitat preference produces 419 differences in their abundance on various seagrasses and other substrates, rather than a 420 presence/absence pattern (Sanchez-Jerez et al., 1999; Vázquez-Luis, Sanchez-Jerez \& Bayle421 Sempere, 2009). A possible scenario is therefore that the northward seagrass range expansion 422 triggered by climate warming after LGM prompted the migration of part of the associated fauna. 423 At the same time, the north-western Mediterranean was likely already inhabited by a local pool 424 of amphipod species derived from the Atlantic (according to the 'biodiversity pump' 425 mechanism), therefore adapted to temperate climatic conditions and able to survive during LGM. 426 Under this hypothesis, it is expected that the CWM assemblages would include many module 427 endemics represented by species with Mediterranean and/or Atlantic distribution (i.e., ME and 428 ATL according to biogeographic classes). Also, CWM and TUN modules should share a relevant 429 number of species (i.e., those originated in the southern refuge and migrated northward with the 430 seagrass). Our analyses showed that all these expectations were verified, supporting the blending 431 between resident, temperate species with the warm-adapted ones spreading from the south with 432 P. oceanica during LGM in explaining the current richness of amphipod fauna in CWM. 


\section{CONCLUSIONS}

435

436 To our knowledge, this study is the first trying to assess the pattern of co-occurrence of

437 Mediterranean benthic amphipod assemblages associated with a peculiar habitat, such as $P$.

438 oceanica meadows. A network approach based on modularity has proven useful in detecting the

439 biogeographic subdivisions of assemblages and in assessing biogeographic roles of associated

440 localities. Our results provide a new perspective on the less studied southern Mediterranean,

441 which may gain a relevant place in the origin of the basin biodiversity as a LGM refuge, besides

442 confirming the known role of the Central Western Mediterranean area as a 'biodiversity pump'

443 from the Atlantic. Our findings also suggest how the distribution of amphipod diversity in $P$.

444 oceanica meadows stems from complex interactions between present and past geographic

445 barriers, local species adaptation, and the biogeography of the host plant.

446 To this end, comparative phylogeographical studies can be used to verify the assumptions

447 made in this study, in order to clarify the history of the biogeographical modules identified. This

448 can open the road to a series of studies aimed at deepening the knowledge of the most common

449 and abundant species shared by modules, to identify the centre of evolution and/or dispersion of

450 amphipods within the Mediterranean. For instance, a comparative phylogeography between

451 congeneric species shared by the TUN and CWM modules but showing different distributions

452 (e.g., species belonging to genera Apolochus, Ampithoe, Dexamine) can help both disentangling

453 the role of the southern basin in the diversity of amphipods and testing for the hypothesis of a

454 convergence between the ecological and evolutionary outcomes of amphipods and seagrass in

455 the Mediterranean basin. 


\section{REFERENCES}

458

Arnaud-Haond S, Migliaccio M, Diaz Almela E, Teixeira S, Van De Vliet MS, Alberto F, Procaccini G, Duarte CM. Serrão EA. 2007. Vicariance patterns in the Mediterranean Sea: eastwest cleavage and low dispersal in the endemic seagrass Posidonia oceanica. Journal Of Biogeography 34(6):963-976 DOI: 10.1111/j.1365-2699.2006.01671.x

463

Arvanitidis C, Bellan G, Drakopoulos P, Valavanis V, Dounas C, Koukouras A, Eleftheriou A. 2002. Seascape biodiversity patterns along the Mediterranean and the Black Sea: lessons from the biogeography of benthic polychaetes. Marine Ecology Progress Series 244:139-152 DOI: $10.3354 /$ meps 244139 .

468

Baty F, Facompré M,Wiegand J, Schwager J, Brutsche MH. 2006. Analysis with respect to instrumental variables for the exploration of microarray data structures. BMC Bioinformatics 7(1):422 DOI: 10.1186/1471-2105-7-422.

472 macro-invertebrate assemblages associated with Posidonia oceanica meadows. Acta Adriatica 52(2):201-214.

476

Bellan-Santini D, Ruffo S. 2003. Biogeography of benthic marine amphipods in Mediterranean Sea. Biogeographia-The Journal of Integrative Biogeography. 24(1).

479

Bellisario B. 2018. Conserving migration in a changing climate, a case study: The Eurasian spoonbill, Platalea leucorodia leucorodia. Biological Conservation 217:222-231 DOI: 10.1016/j.biocon.2017.11.013.

483

484

Bellisario B, Camisa F, Nascetti G, Lattanzi L, Cimmaruta R. 2016. Spatial and temporal variation of coastal mainland $v$ s. insular amphipod assemblages on Posidonia oceanica meadows. Marine Biodiversity 46(2):355-363 DOI: 10.1007/s12526-015-0367-z.

Berline L, Rammou AM, Doglioli A, Molcard A, Petrenko A. 2014. A connectivity-based eco489 regionalization method of the Mediterranean Sea. PLOS ONE 9(11):e111978.

490

Bianchi CN. 2007. Biodiversity issues for the forthcoming tropical Mediterranean Sea. In: Relini $\mathrm{G}$, Ryland J, eds. Biodiversity in enclosed seas and artificial marine habitats. Developments in Hydrobiology. Dordrecht: Springer Verlag, 7-21. 
495 Bianchi CN, Morri C. 2000. Marine biodiversity of the Mediterranean Sea: situation, problems 496 and prospects for future research. Marine Pollution Bulletin 40(5):367-376 DOI: 10.1016/S0025$497326 X(00) 00027-8$.

498

499

500

501

502

503

504

505

506

507

508

509

510

511

512

513

514

515

516

517

518

519

520

521

522

523

524

525

526

527

528

529

530

531

532

533

534

Bianchi CN, Morri C, Chiantore M, Montefalcone M, Parravicini V, Rovere A. 2012.

Mediterranean Sea biodiversity between the legacy from the past and a future of change. In: Stambler N, ed.) Life in the Mediterranean Sea: a look at habitat changes. New York: Nova Science Publishers, 1-56.

Bloomfield NJ, Knerr N, Encinas-Viso F. 2018. A comparison of network and clustering methods to detect biogeographical regions. Ecography 41:1-10 DOI: 10.1111/ecog.02596.

Boudouresque CF. 2004. Marine biodiversity in the Mediterranean: status of species, populations and communities. Scientific Reports of Port-Cros national Park 20:97-146.

Boudouresque CF, Mayot M, Pergent G. 2006. The outstanding traits of the functioning of the Posidonia oceanica seagrass ecosystem. Biologia Marina Mediterranea 13:109-113.

Buia MC, Gambi MC, Zupo V. 2000. Structure and functioning of Mediterranean seagrass ecosystems: an overview. Biologia Marina Mediterranea 2:167-190.

Camisa F, Abbattista C, Bellisario B, Angeletti D, Lattanzi L, Cimmaruta R. 2017. Seasonal variations of amphipod assemblages in a Posidonia oceanica (Linnaeus) Delile, 1813 meadow from the central Tyrrhenian Sea (Italy). Crustaceana 90:1319-1335 DOI: 10.1163/1568540300003725 .

Carstensen DW, Olesen JM. 2009. Wallacea and its nectarivorous birds: nestedness and modules. Journal Of Biogeography 36(8):1540-1550 DOI: 10.1111/j.1365-2699.2009.02098.x.

Carstensen DW, Dalsgaard B, Svenning J, Rahbek C, Fjeldså J, Sutherland WJ, Olesen JM. 2012. Biogeographical modules and island roles: a comparison of Wallacea and the West Indies. Journal Of Biogeography 39(4):739-749 DOI: 10.1111/j.1365-2699.2011.02628.x.

Carstensen DW, Lessard J, Holt BG, Krabbe Borregaard M, Rahbek C. 2013. Introducing the biogeographic species pool. Ecography 36(12):1310-1318 DOI: 10.1111/j.16000587.2013.00329.x.

Chefaoui RM, Duarte CM, Serrão EA. 2017. Palaeoclimatic conditions in the Mediterranean explain genetic diversity of Posidonia oceanica seagrass meadows. Scientific Reports 7(1):2732 DOI: $10.1038 / \mathrm{s} 41598-017-03006-2$. 
536 Coll M, Piroddi C, Steenbeek J, Kaschner K, Ben Rais Lasram F, Aguzzi J, Ballesteros E,

537 Bianchi CN, Corbera J, Dailianis T, Danovaro R, Estrada M, Froglia C, Galil BS, Gasol JM,

538 Gertwagen R, Gil J, Guilhaumon F, Kesner-Reyes K, Kitsos MS, Koukouras A, Lampadariou N,

539 Laxamana E, López-Fé de la Cuadra CM, Lotze HK, Martin D, Mouillot D, Oro D, Raicevich S,

540 Rius-Barile J, Saiz-Salinas JI, San Vicente C, Somot S, Templado J, Turon X, Vafidis D,

541 Villanueva R, Voultsiadou E. 2010. The biodiversity of the Mediterranean Sea: estimates,

542 patterns, and threats. PloS One 5(8):e11842. DOI: 10.1371/journal.pone.0011842.

543

544 Como S, Magni P, Baroli M, Casu D, De Falco G, Floris A. 2008. Comparative analysis of

545 macrofaunal species richness and composition in Posidonia oceanica, Cymodocea nodosa and

546 leaf litter beds. Marine Biology 153(6):1087-1101 DOI: 10.1007/s00227-007-0881-z.

547

548 Danovaro R, Gambi C, Lampadariou N, Tselepides A. 2008. Deep-sea nematode biodiversity in 549 the Mediterranean basin: testing for longitudinal, bathymetric and energetic gradients.

550 Ecography 31(2):231-244 DOI: 10.1111/j.0906-7590.2008.5484.x.

551

552 Danovaro R, Company JB, Corinaldesi C, D'Onghia G, Galil B, Gambi C, Gooday AJ, 553 Lampadariou N, Luna GM, Morigi C, Olu K, Polymenakou P, Ramirez-Llodra E, Sabbatini A, 554 Sarda F, Sibuet M, Tselepides A. 2010. Deep-sea biodiversity in the Mediterranean Sea: The 555 known, the unknown, and the unknowable. PloS One 5(8):e11832 DOI:

556 10.1371/journal.pone.0011832.

557

558

559

Diviacco G. 1988. I Crostacei Anfipodi di alcune praterie di Posidonia oceanica pugliesi. Thalassia Salentina 18:131-139.

560

561

Falco P, Griffa A, Poulain P, Zambianchi E. 2000. Transport properties in the Adriatic Sea as

562 deduced from drifter data. Journal of Physical Oceanography 30(8):2055-2071 DOI:

563 10.1175/1520-0485(2000)030<2055:TPITAS>2.0.CO;2.

564

565 Fletcher Jr RJ, Revell A, Reichert BE, Kitchens WM, Dixon JD, Austin JD. 2013. Network 566 modularity reveals critical scales for connectivity in ecology and evolution. Nature

567 Communications 4:2572 DOI: 10.1038/ncomms3572.

568

569 Fortunato S. 2010. Community detection in graphs. Physics Reports 486:75-174 DOI:

570 10.1016/j.physrep.2009.11.002.

571

572 Gambi MC, Lampadariou N, Danovaro R. 2010. Latitudinal, longitudinal and bathymetric

573 patterns of abundance, biomass of metazoan meiofauna: importance of the rare taxa and 
574 anomalies in the deep Mediterranean Sea. Advances in Oceanography and Limnology 1:167-197

575 DOI: $10.4081 /$ aiol.2010.5299.

576

577 Gambi MC, Lorenti M, Russo GF, Scipione MB, Zupo V. 1992. Depth and seasonal distribution

578 of some groups of the vagile fauna of the Posidonia oceanica leaf stratum: structural and trophic 579 analyses. Marine Ecology 13(1):17-39 DOI: 10.1111/j.1439-0485.1992.tb00337.x.

580

581 Gerovasileiou V, Voultsiadou E. 2012. Marine caves of the Mediterranean Sea: a sponge

582 biodiversity reservoir within a biodiversity hotspot. PLoS One 7(7):e39873 DOI:

583 10.1371/journal.pone.0039873.

584

585

Guimerà R, Amaral LAN. 2005. Functional cartography of complex metabolic networks. Nature 586 433(7028):895 DOI: 10.1038/nature03288.

587

588

Hewitt GM. 1999. Post-glacial re-colonization of European biota. Biological Journal of Linnean

589 Society 68:87-112 DOI: 10.1006/bijl.1999.0332.

590

591

Hewitt GM. 2000. The genetic legacy of the Quaternary ice ages. Nature 405(6789):907 DOI:

$59210.1038 / 35016000$.

593

594

595

Hewitt GM. 2004. Genetic consequences of climatic oscillations in the Quaternary.

Philosophical Transactions of The Royal Society B 359(1442):183-195 DOI:

596 10.1098/rstb.2003.1388.

597

598

599

600

601

602

603

604

Ignatiades L, Gotsis-Skretas O, Pagou K, Krasakopoulou E. 2009. Diversification of phytoplankton community structure and related parameters along a large-scale longitudinal eastwest transect of the Mediterranean Sea. Journal of Plankton Research 31(4):411-428 DOI: 10.1093/plankt/fbn124.

605

606

Ives AR, Carpenter SR. 2007. Stability and diversity of ecosystems. Science 317(5834):58-62 DOI: $10.1126 /$ science.1133258.

607

Kivelä M, Arnaud-Haond S, Saramäki J. 2015. EDENetworks: A user-friendly software to build and analyse networks in biogeography, ecology and population genetics. Molecular Ecology

608 Resources 15(1):117-122 DOI: 10.1111/1755-0998.12290.

609

610

Lejeusne C, Chevaldonné P, Pergent-Martini C, Boudouresque CF, Pérez T. 2010. Climate

611 change effects on a miniature ocean: the highly diverse, highly impacted Mediterranean Sea.

612 Trends in Ecology and Evolution 25(4):250-260 DOI: 10.1016/j.tree.2009.10.009.

613 
614 Maggs CA, Castilho R, Foltz D, Henzler C, Jolly MT, Kelly J, Olsen J, Perez KE, Stam W, 615 Väinölä R, Viard F, Wares J. 2008. Evaluating signatures of glacial refugia for North Atlantic

616 benthic marine taxa. Ecology 89(11):108-122 DOI: 10.1890/08-0257.1.

617

618 Mazzella L, Scipione MB, Buia MC. 1989. Spatio-Temporal distribution of algal and animal 619 communities in a Posidonia oceanica meadow. Marine Ecology 10(2):107-129 DOI:

620 10.1111/j.1439-0485.1989.tb00069.x.

621

622

Michel LN, Dauby P, Gobert S, Graeve M, Nyssen F, Thelen N, Lepoint G. 2015. Dominant

623 amphipods of Posidonia oceanica seagrass meadows display considerable trophic diversity.

624

Marine Ecology 36:969-981 DOI:10.1111/maec.12194.

625

626

Muñoz Pajares AJ. 2013. SIDIER: Substitution and indel distances to infer evolutionary

627 relationships. Methods in Ecology and Evolution 4:1195-1200 DOI: 10.1111/2041-210X.12118.

628

629

Newman ME, Girvan M. 2004. Finding and evaluating community structure in networks.

630

Physical Review E 69(2):026113 DOI: 10.1103/PhysRevE.69.026113.

631

632 Orlic M, Gacic M, Laviolette P. 1992. The currents and circulation of the Adriatic Sea.

633 Oceanologica Acta 15(2):109-124.

634

635 Pinardi N, Masetti E. 2000. Variability of the large scale general circulation of the Mediterranean

636 Sea from observations and modelling: a review. Palaeogeography, Palaeoclimatology,

637 Palaeoecology 158(3):153-173 DOI: 10.1016/S0031-0182(00)00048-1.

638

639

Pinnegar J, Polunin N, Francour P, Badalamenti F, Chemello R, Harmelin-Vivien M, Hereu B,

640 Milazzo M, Zabala M, D’Anna G, Pipitone C. 2000. Trophic cascades in benthic marine

641 ecosystems: lessons for fisheries and protected-area management. Environmental Conservation

642 27(2):179-200 DOI: 10.1017/S0376892900000205.

643

644 R Development Core Team. 2018. R: A language and environment for statistical computing. R

645 Foundation for Statistical Computing, Vienna, Austria, http://www.r-project.org/.

646

647 Robinson AR, Malanotte-Rizzoli P, Hecht A, Michelato A, Roether W, Theocharis A, Ünlüata

648 Ü, Pinardi N, Artegiani A, Bergamasco A, Bishop J, Brenner S, Christianidis S, Gacic M,

649 Georgopoulos D, Golnaraghi M, Hausmann M, Junghaus HG, Lascaratos A, Latif MA, Leslie

650 WG, Lozano CJ, Og، uz T, Özsoy E, Papageorgiou E, Paschini E, Rozentroub Z, Sansone E,

651 Scarazzato P, Schlitzer R, Spezie GC, Tziperman E, Zodiatis G, Athanassiadou L, Gerges M,

652 Osman M. 1992. General circulation of the Eastern Mediterranean. Earth-Science Reviews

653 32:285-309 DOI: 10.1016/0012-8252(92)90002-B. 
654

655 Rohling EJ, Braun K, Grant K, Kucera M, Roberts AP, Siddall M, Trommer G. 2010.

656 Comparison between Holocene and Marine Isotope Stage-11 sea-level histories. Earth and

657 Planetary Science Letters 291:97-105 DOI: 10.1016/j.eps1.2009.12.054.

658

659 Rozenfeld AF, Arnaud-Haond S, Hernández-García E, Eguíluz VM, Serrão EA, Duarte CM.

660 2008. Network analysis identifies weak and strong links in a metapopulation system.

661 Proceedings of the National Academy of Science of the United States of America 105(48):18824-

66218829 DOI: 10.1073/pnas.0805571105.

663

664 Sánchez-Jerez P, Carberá Cebrian C, Ramos Esplá AA. 2000. Influence of the structure of

665 Posidonia oceanica meadows modified by bottom trawling on crustacean assemblages:

666 comparison of amphipods and decapods. Scientia Marina 64(3):319-326.

667

668

Scipione MB et al. 1996. Vagile fauna of the leaf stratum of Posidonia oceanica and Cymodocea

669 nodosa in the Mediterranean Sea. - Seagrass biology. Perth: The University of Western

670 Australia, 249-260.

671

672 Scipione MB. 1998. Amphipod biodiversity in the foliar stratum of shallow-water Posidonia

673 oceanica beds in the Mediterranean Sea. In: Schram FR, von Vaupel Klein JC, eds. Crustaceans

674 and the biodiversity crisis. Proceedings of the Fourth International Crustacean Congress.

675 Leiden: Brill, 649-662.

676

677 Scipione MB, Zupo V. 2010. Crustacean amphipods from the seagrasses Zostera marina,

678 Cymodocea nodosa and Posidonia oceanica in the Adriatic Sea (Italy): a first comparison.

679 Zoologica Baetica 21:15-32.

680

681 Serra A, Innocenti AM, Di Maida G, Calvo S, Migliaccio M, Zambianchi E, Pizzigalli C, 682 Arnaud-Haond S, Duarte CM, Serrao EA, Procaccini G. 2010. Genetic structure in the

683 Mediterranean seagrass Posidonia oceanica: disentangling past vicariance events from 684 contemporary patterns of gene flow. Molecular Ecology 19:557-568 DOI: 10.1111/j.1365685 294X.2009.04462.x.

686

687 Sevastou K, Lampadariou N, Polymenakou PN, Tselepides A. 2013. Benthic communities in the 688 deep Mediterranean Sea: exploring microbial and meiofaunal patterns in slope and basin 689 ecosystems. Biogeosciences 10:4861-4878 DOI: 10.5194/bg-10-4861-2013.

690

691 Stauffer D, Aharony A. 1992. Introduction to Percolation Theory. London: Taylor and Francis. 692 
693 Sturaro N, Lepoint G, Perez-Perrera A, Vermeulen S, Panzalis P, Navone A, Gobert S. 2014.

694 Seagrass amphipod assemblages in a Mediterranean marine protected area: a multiscale

695 approach. Marine Ecology Progress Series 506:175-192 DOI:

696

697 Sturaro N, Lepoint G, Vermeulen S, Gobert S. 2015. Multiscale variability of amphipod

698 assemblages in Posidonia oceanica meadows. Journal of Sea Research 95:258-271 DOI:

699 10.1016/j.seares.2014.04.011.

700

701 Tecchio S, Ramirez-Llodra E, Sardà F, Company JB. 2010. Biodiversity patterns of deep-sea

702 benthic megafauna on western and central Mediterranean basins. Scientia Marina 75:341-350.

703

704 Thebault E. 2013. Identifying compartments in presence-absence matrices and bipartite 705 networks: insights into modularity measures. Journal of Biogeography 40(4):759-768 DOI:

706 10.1111/jbi.12015.

707

708 Valentine JF, Duffy J. 2006. The central role of grazing in seagrass ecology. in Larkum AWD,

709 Orth RJ, Duarte CM, eds. Seagrasses: biology, ecology and conservation. Springer, Dordrecht,

710 The Netherlands, 463-501.

711

712 Vázquez-Luis M, Sanchez-Jerez P, Bayle-Sempere JT. 2009. Comparison between amphipod

713 assemblages associated with Caulerpa racemosa var. cylindracea and those of other

714 Mediterranean habitats on soft substrate. Estuarine Coastal and Shelf Science 84(2):161-170

715 DOI: 10.1016/j.ecss.2009.04.016.

716

717 Vilhena DA, Antonelli A. 2015. A network approach for identifying and delimiting

718 biogeographical regions. Nature Communications 6:6848 DOI: 10.1038/ncomms7848.

719

720

Zakhama-Sraieb R, Ramzi Sghaier Y, Charfi-Cheikhrouha F. 2006. Is amphipod diversity related

721

to the quality of Posidonia oceanica beds? Biologia Marina Mediterranea 13(4):174-180.

722

723 Zakhama-Sraieb R, Ramzi Sghaier Y, Charfi-Cheikhrouha F. 2011. Community structure of

724 amphipods on shallow Posidonia oceanica meadows off Tunisian coasts. Helgoland Marine

725 Research 65(2):203 DOI: 10.1007/s10152-010-0216-1.

726

727 Zenetos A, Mačić V, Jaklin A, Lipej L, Poursanidis D, Cattaneo-Vietti R, Beqiraj S, Betti F,

728 Poloniato D, Kashta L, Katsanevakis S, Crocetta F. 2016. Adriatic 'opisthobranchs'(Gastropoda,

729 Heterobranchia): shedding light on biodiversity issues. Marine Ecology 37(6):1239-1255 DOI:

$73010.1111 / \mathrm{maec} .12306$. 
Figure 1

\section{Overview of the Mediterranean Sea with reference localities}

Arrows indicate the main circulation patterns and red lines the main barriers: 1, Gibraltar Strait; 2, AlmeriaOran Front; 3, Ibiza Channel; 4, Balearic Front; 5, Sicily Channel; 6, Otranto Strait. For acronyms, see Supplemental Materials \& Methods.

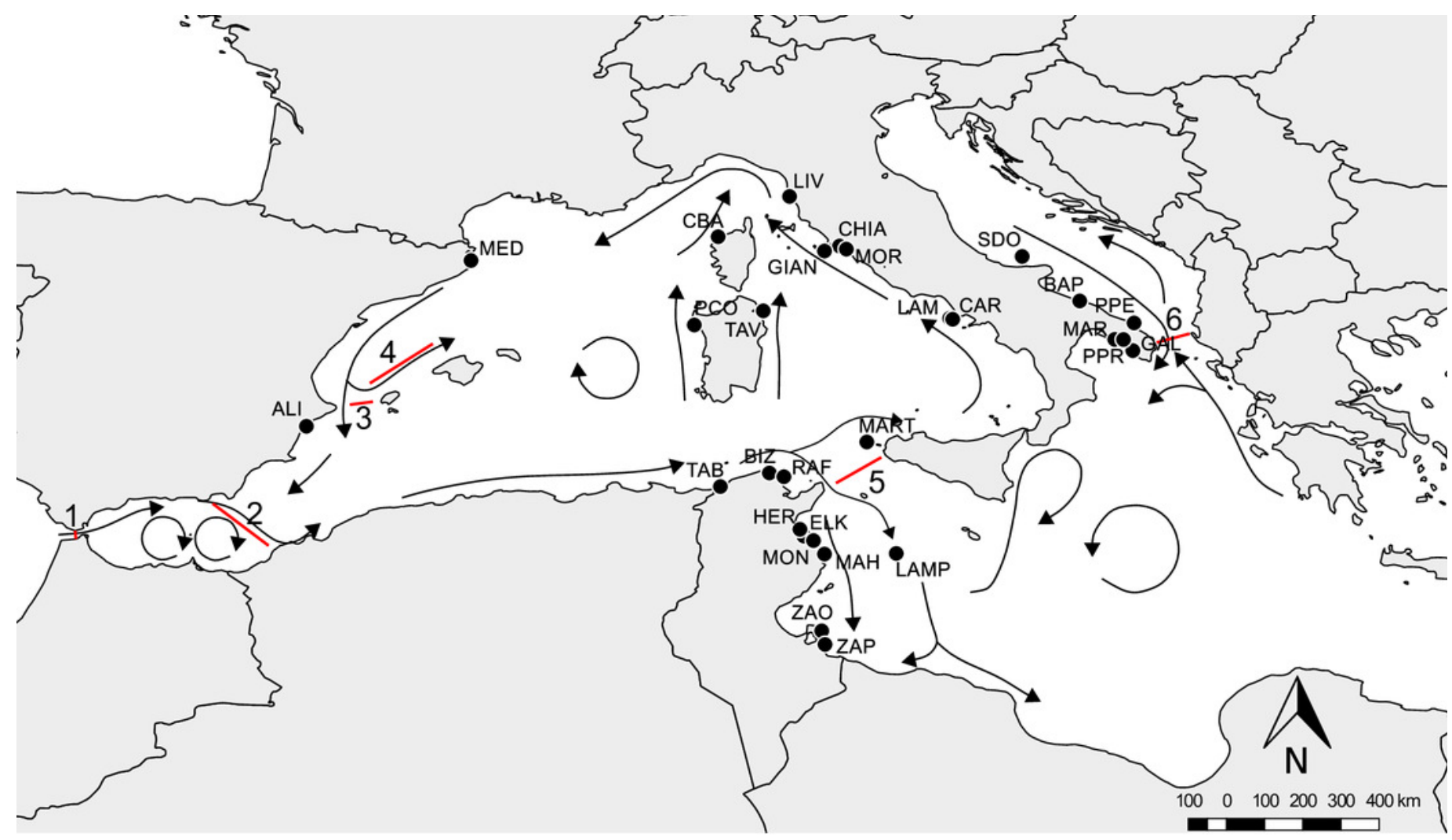




\section{Figure 2}

Spatial distribution of modules, network structure and biogeographic roles of localities.

(a) Spatial distribution of the four modules identified: yellow, CWM; blue, TUN; green, ION;

red, ADR. (b) Network visualization of biogeographic modules with associated amphipod species (black dots). (c) Plot showing the biogeographic role of localities. Coordinates / and $r$ describe the species richness of localities and the geographical distribution of associated species, respectively. Node size is proportional to species diversity. R1, peripherals: few local and regional species; R2, non-hub connectors: few local and many regional species; R3, provincial hubs: many local and few regional species; R4, connector hubs: many local and regional species (revised after Carstensen et al., 2012). For locality acronyms, see Supplemental Materials \& Methods S1. 

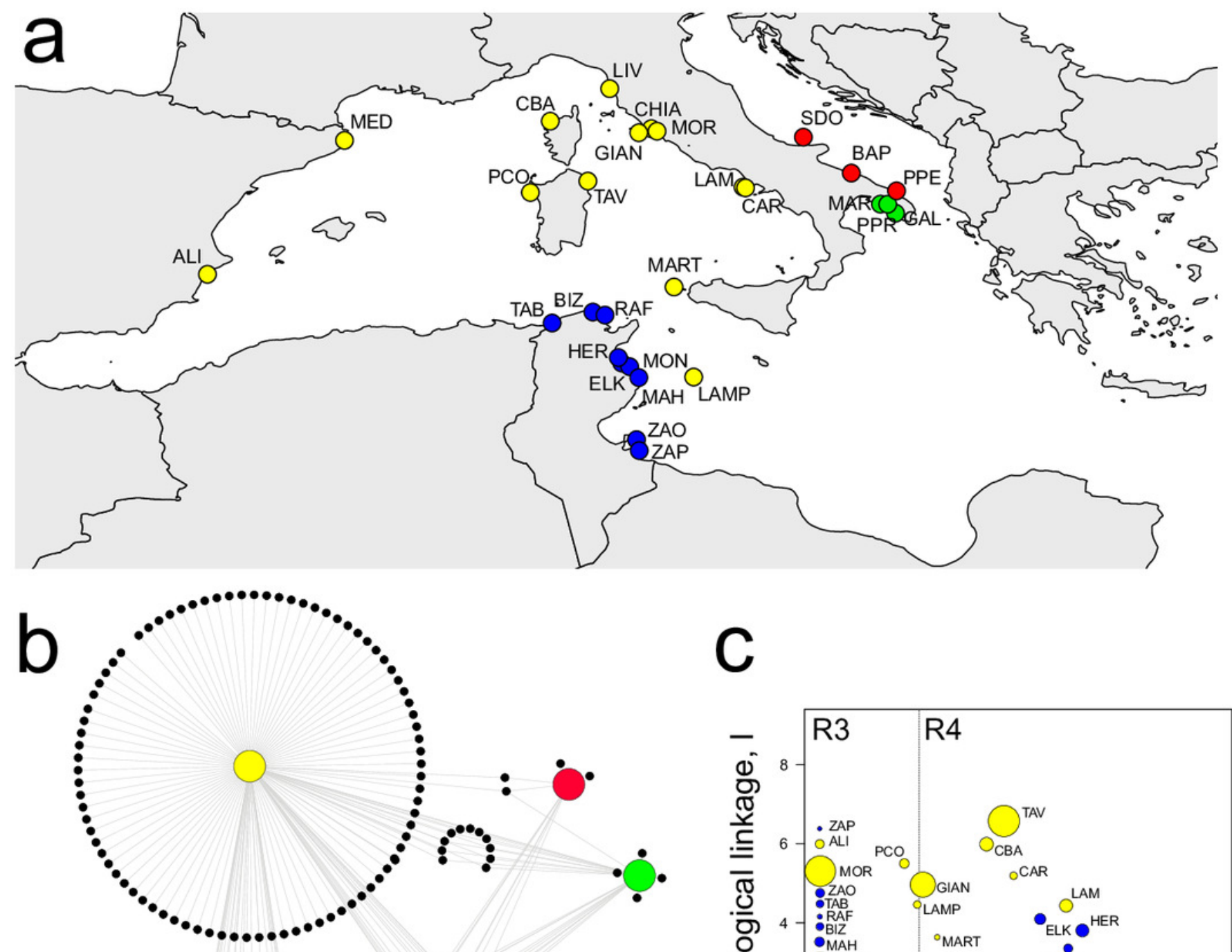

C
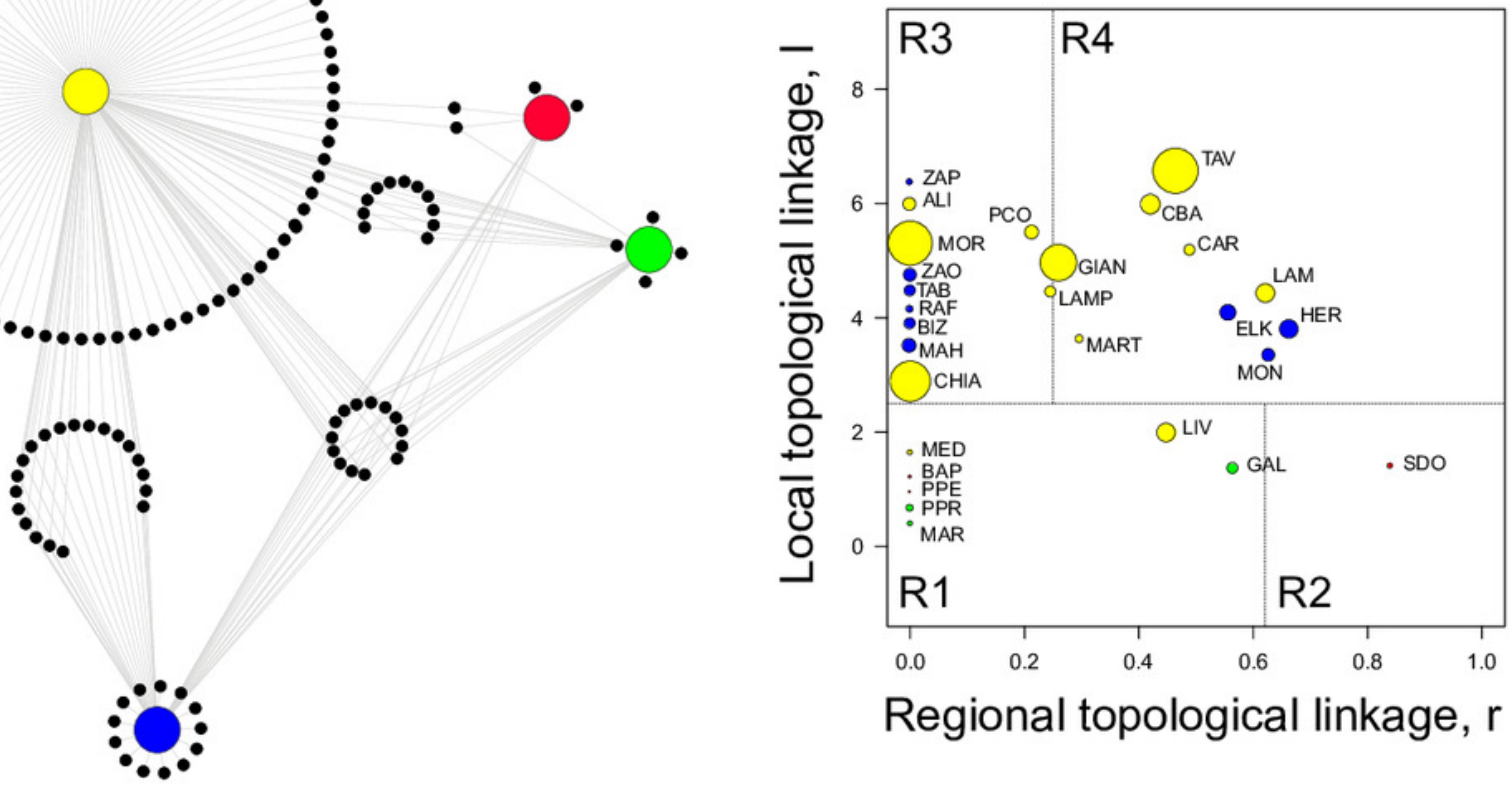

Regional topological linkage, $r$ 
Figure 3

Between-Group Correspondence Analysis (BGCA) of localities based on the nine speciesbiogeographic classes according to literature.

Colours indicate the identified modules (see Fig. 2a) and different shapes correspond to the biogeographic role of localities (see top-right box). Dashed arrows indicate the nine speciesbiogeographic classes (revised after Bellan-Santini \& Ruffo, 2003): COSMP, Cosmopolitan; INDP, Indo-Pacific; AFR, African coasts from Ceuta to Cap Vert; ATL, Atlantic coasts from Spain to Britain; NATL, North Atlantic from Norway to Arctic Sea; WM, West Mediterranean; EM, East Mediterranean; ADR, Adriatic Sea; ME, Mediterranean endemics. For locality acronyms, see Supplemental Materials \& Methods S1.

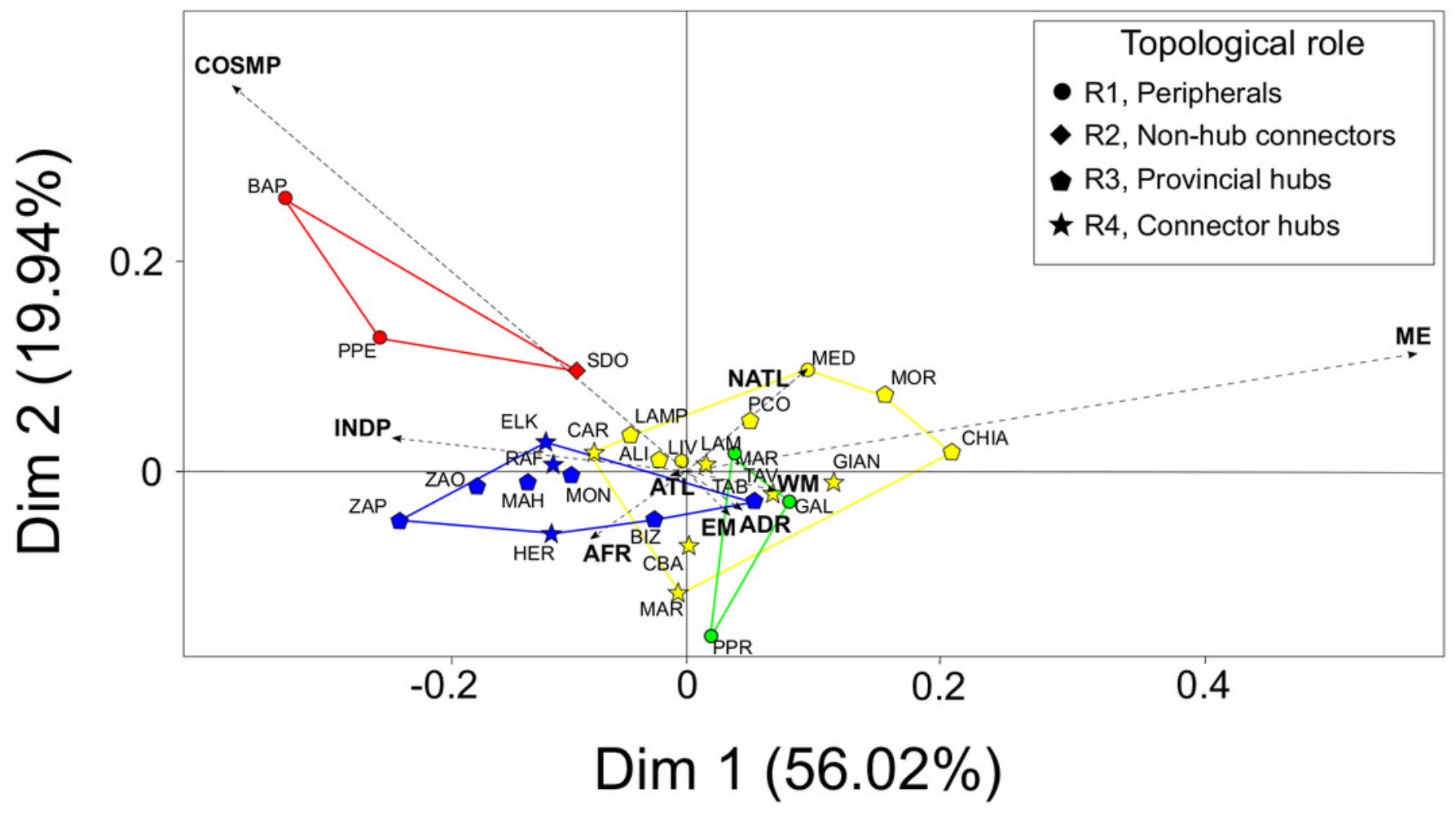




\section{Table $\mathbf{1}$ (on next page)}

Modular subdivision of sampling localities.

$L$ is the number of localities in each module;s the total number of species. Module exclusive is the percentage of species exclusively present in a single module; ME and COSMP are the percentage of species in each module belonging to the Mediterranean Endemics (ME) and Cosmopolite (COSMP) biogeographic classes (see Supplemental Materials \& Methods). 


\begin{tabular}{cccccc} 
Module & $L$ & $s$ & Module exclusive (\%) & $\begin{array}{c}\text { Mediterranean endemics } \\
\text { (ME\%) }\end{array}$ & $\begin{array}{c}\text { Mediterranean cosmopolite } \\
\text { (COSMP\%) }\end{array}$ \\
\hline CWM & 11 & 130 & 64.7 & 16.7 & 4.8 \\
TUN & 9 & 46 & 27.6 & 7.3 & 7.3 \\
ION & 3 & 26 & 15.4 & 13 & 4.3 \\
ADR & 3 & 15 & 18.4 & 9 & 27.3 \\
\hline
\end{tabular}

1 